\title{
An overview of IPA Braille: An updated tactile representation of the International Phonetic Alphabet
}

\author{
Robert Englebretson \\ Department of Linguistics, Rice University \\ reng@rice.edu
}

This article provides an overview of IPA Braille, revised and updated by Englebretson (2008) under the auspices of the International Council on English Braille (ICEB). After a brief introduction to braille as a writing system and a review of the disparate braille notations formerly used for phonetics, the author discusses the need for a single, up-todate, linguistically-informed braille notation for the IPA. The author then outlines the rationale and procedures used in developing IPA Braille, and presents an appendix of the complete charts showing the braille equivalents for all symbols of the current IPA (revised to 2005). This article is relevant to phoneticians interested in applications of the IPA, linguists interested in writing systems, instructors who may have blind students enrolled in phonetics and linguistics courses, and especially to blind students and professionals needing access to a complete, updated braille IPA notation. The publication of the full braille charts in JIPA ensures that IPA Braille is available to the wider community of phoneticians and linguists, who typically do not have access to the literature from specialized braille publishing houses.

\section{Introduction}

For many people who cannot read standard print, braille provides a crucial means of literacy and independence. Through braille, many blind people enjoy access to educational, professional, and leisure materials, and are thereby fully able to participate in, and contribute to, society on an equal footing with sighted colleagues. While a host of additional factors of course contributes to any blind individual's success and independence (e.g. positive societal attitudes about blindness, high self-expectations, opportunities for education and exploration, etc.), braille literacy is often implicated in higher levels of employment, financial security, education, and greater personal independence (Eldridge 1979; Schroeder 1989, 1996, 2000; Stephens 1989; Ryles 1996, 2000). For this reason, associations of blind people, e.g. the American Council of the Blind and the National Federation of the Blind (both in the United States) and the Royal National Institute of Blind People (in the United Kingdom), among many other organizations worldwide, actively work to encourage braille literacy. Similarly, UNESCO (United Nations Educational, Scientific and Cultural Organization) promotes the teaching and use of braille in developing countries (UNESCO 1990), and a few dedicated individuals are also devoting their careers to this cause (see e.g. Tenberken 2003 for an overview of her work with blind children in Tibet). 
In this regard, it is noteworthy that the International Phonetic Association has also recognized the importance of braille. As Edith E. Quick commented in a published announcement of the very first braille notation of the IPA (developed by Merrick \& Potthoff

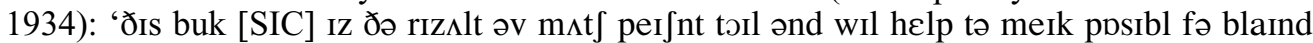
stjudnts ə st $\Lambda$ di fə wit $\int$ JeI meI bi pri-عminəntlı sjutId' (Quick 1936: 51). Despite the rather stereotypic nature of Quick's assumption that a blind person 'may be preeminently suited' for a career in the language sciences, as opposed to any other career of his or her choosing, the gist of this comment is still valid: the existence of a braille notation for the IPA does indeed afford blind people a means of achieving literacy and full participation as students or professionals in this field (see also Wells-Jensen 2005).

However, because there have been at least two distinct notational systems for representing IPA in braille (see BAUK 1990 for the braille IPA used in the United Kingdom, and BANA 1997a for the braille IPA used in the United States and Canada; see also IPA 1999: 32), and because these systems are mutually unintelligible, incompatible with one another, and lagging decades behind the official updates to the inkprint IPA, the situation for braille readers in the language sciences has been far from optimal. For this reason, beginning in early 2005, the present author, who is himself a braille reader and a professional in the field of linguistics, has been working closely with the International Council on English Braille (ICEB) to develop an updated, unified, and robust system of IPA Braille. (See the announcement and call for input posted on LinguistList 16.3138: http://linguistlist.org/issues/16/16-3138.html, as well as the announcement of the draft project published in 2006 in the IPA News section of JIPA 36(1), page 133.) After two years of review, testing, and comments from braille readers and from anyone else wishing to give input, IPA Braille (Englebretson 2008) has been officially adopted by ICEB. A print booklet and two-volume braille edition has been produced by CNIB (Canadian National Institute for the Blind), and is available world-wide in hardcopy braille or via the ICEB web site (http://www.iceb.org/icebipa.htm).

The purpose of this article is to provide a thorough overview of IPA Braille. After a brief introduction to braille as a writing system and a discussion of the diverse braille notations formerly used for phonetics, I will outline the importance of a single, up-to-date, linguistically-informed braille notation for the IPA. I will then present the rationale and procedures used in developing IPA Braille, discuss the composition of IPA Braille symbols, and include an appendix of the complete IPA Braille charts (IPA revised to 2005). This article is relevant to phoneticians interested in applications of the IPA, linguists interested in writing systems, instructors who may have blind students enrolling in linguistics and phonetics courses, and especially to blind students and professionals needing access to a complete, updated braille IPA notation. The publication of the full braille charts in JIPA makes IPA Braille accessible to the wider community of phoneticians and linguists, rather than relegating it only to the specialized braille publishing houses of which most linguists are unaware, and whose publications typically fall under the radar of professional literature indexes and databases.

\section{Brief introduction to braille}

This section presents a basic overview of general characteristics of braille as a writing system. It is cursory by design, seeking only to acquaint the reader with sufficient background knowledge to approach IPA Braille, which is the core of the article. Readers desiring a more detailed discussion of braille may consult a variety of sources. For in-depth research on the perceptual and cognitive underpinnings of braille, see Lorimer (1996) and Millar (1997). For an overview of neuroimaging research on braille reading and the use of the primary visual cortex in blind braille readers, see Sadato (2005). For a recent biography of Louis Braille, the inventor of this tactile writing system which bears his name, see Mellor (2006). For a history 
of tactile writing systems and the development of braille see Lorimer (1996) and papers in NLS (2000). For a general overview of braille world-wide, see Hampshire (1981) and UNESCO (1990). For specifics on all aspects of English Braille as used in the United States and Canada, consult BANA (1994), and for English Braille usage in the United Kingdom, see BAUK (2004).

Braille itself is not a language (cf. Wittenstein 1993), but, just like inkprint writing, is a representation of a language. In other words, braille is a rule-based cipher for converting an inkprint writing system to the tactile modality. Braille representations exist for the Roman, Cyrillic, Greek, Arabic, Hebrew, and Hangul alphabets, among others. Languages using logographic print writing systems are typically rendered in braille either through romanization or by means of a local syllabary or alphabet; for example, Mandarin Chinese braille consists of symbols for syllable initials and syllable finals, based originally on the print Zhùyinn Fúhào syllabic alphabet (also known as 'bopomofo'). For more details about braille in specific languages, see UNESCO (1990), which also contains contact information for the relevant braille authorities - the legislative bodies responsible for the design and implementation of braille in a given language or country.

Braille is a system of raised dots, designed to be read by laterally scanning the ball of the fingertips across a line of embossed paper, or along the pins of a refreshable braille display (an electro-mechanical device that serves as the output for a computer or PDA - see Dixon 2000 for more details). Competent braille readers may achieve reading speeds upwards of 190 words per minute (Millar 1997: 67), although there is of course considerable individual variation among reading speeds based on age and experience, proficiency, and the type of material being read. The foundational, universal unit of braille is a $2 \times 3$ matrix of dots known as the braille cell: ::. Dots in the braille cell are referred to by number, where the three dots in the left-hand column are numbered $1-3$ from top to bottom ( $\because$ dot $1, \therefore \operatorname{dot} 2, \because \vdots \operatorname{dot} 3)$ and the dots in the right-hand column are numbered $4-6$ from top to bottom $(\because \because \operatorname{dot} 4, \because \operatorname{dot}$ 5 , : dot 6). For example, the braille symbol : (Roman letter t) is referred to as dots 2345 . Braille is therefore essentially a six-bit binary system - there are six dots, and a dot is either raised or not raised - meaning there are exactly $64\left(2^{6}\right)$ possible characters, consisting of 63 dot combinations, and the blank space where no dots are raised. The 63 symbols derived from the six-dot braille cell form the basis of all braille writing systems worldwide, although the exact meaning of each symbol is language- and genre-specific. Beginning in the 1970s, an eight-dot braille cell consisting of two columns of four dots each was developed to encode eight-bit ASCII characters. While this does allow for the representation of $256\left(2^{8}\right)$ unique characters (including the blank space), the use of eight-dot braille is generally avoided in most contexts, due to logistical problems and perceptual difficulties, an issue to which I will return in section 4.2 below.

Two notes are in order regarding the differences between actual embossed braille and the simulated inkprint braille font used in this article (SimBraille ${ }^{\mathrm{TM}}$ from Duxbury Systems, Inc.). First, in simulated braille a raised dot is indicated by a filled circle, while the lack of a dot is indicated by a small point. This is designed solely for the convenience of people reading braille by sight; when braille is read tactually, there is of course no mark to indicate the absence of a dot. Secondly, the simulated braille characters are considerably smaller than embossed braille, in which dot height, dot spacing, and spacing between cells and lines are all strictly regulated based on uniform standards.

Table 1 presents the braille mapping for the lowercase letters $\mathrm{a}-\mathrm{z}$ of the Roman alphabet. Notice that the first ten letters of the alphabet, $a-j$, are formed solely by using the dots in the top two rows of the braille cell. The next ten letters, $\mathrm{k}-\mathrm{t}$, are homologous to the first ten, plus the addition of dot 3 . The remaining letters, $\mathrm{u}-\mathrm{z}$, continue this pattern, this time adding dots 36 to the upper-cell base. The exception to this pattern is the letter w, which was not used in French when Louis Braille developed this alphabet in the early 1820 s.

The remaining 37 non-alphabetic braille symbols not shown in this table fulfill a variety of functions: punctuation, whole- or part-word letter groups, mode or contraction indicators, 
Table 1 The Roman alphabet in Braille.

\begin{tabular}{|c|c|c|c|c|c|c|c|c|c|}
\hline$\because$ & $:$ & $\because$ & $\because$ & $\because$ & $:$ & :: & : & $\therefore$ & $\therefore$ \\
\hline a & b & c & d & e & $f$ & $g$ & h & i & j \\
\hline$\vdots$ & $:$ & $\ddot{a}$ & $\because$ & $\because$ & $:$ & :: & : & $\therefore$ & : \\
\hline k & I & $\mathrm{m}$ & $\mathrm{n}$ & 0 & $p$ & $q$ & r & $S$ & $\mathrm{t}$ \\
\hline$\therefore$ & $\vdots$ & : & $\ddot{:}$ & :: & $\because$ & & & & \\
\hline u & v & w & $x$ & $y$ & z & & & & \\
\hline
\end{tabular}

and (in some languages) letters with diacritics. In English literary braille (both American and current British usage), there are no unique characters for uppercase letters; rather, uppercase letters are composite two-cell characters, created by preceding the corresponding lowercase letter with $:($ dot 6$)$, e.g., $\because: \vdots$ A, $\vdots:$ B, etc. Because braille takes up considerably more space than print, and in order to facilitate faster reading, the literary braille codes for many languages also employ a series of short forms called 'contractions', where frequent words and groups of letters are represented by unique symbols (e.g. in English literary braille :: 'the', :: 'and', :: 'ed'), or where single letters or groups of letters represent whole words (: $:$ 'but', : 'can', .. . :: 'as'; : :: 'tomorrow', etc.). English literary braille contains 189 contractions, the discussion of which lies well outside the scope of this article; for a linguistically-informed overview, see Hamp \& Catón (1984). All contractions are language- and braille-code-specific.

Non-braille readers are often surprised to learn that a particular braille character does not have universal meaning across languages, or even among genres within the same language. For example, in contrast to print, which has a set of ten symbols universally understood as Arabic numerals $(1,2,3,4, \ldots 0)$, there are at least three distinct ways of writing Arabic numerals in braille. In many braille systems (including English literary braille), the numerals $1-0$ are formed by preceding the letters a-j with the braille numeric indicator $: \vdots$ (dots 3456 ), e.g. $: \because 1,: \vdots: 2, \ldots: \vdots: \vdots 10, \ldots: \vdots:: \vdots 111$, etc. Outside of English literary braille, there are at least two other widely-used systems for indicating numerals: in the braille system for math and science used in the United States and Canada, known as the Nemeth Code (Nemeth 1972), the digits 1-0 are represented by the letters a-j shifted down one row in the braille cell $(\because 1,: \vdots 2, \because 33, \ldots \therefore 0)$; and in a notational system widely used in Europe for computer braille, the digits $1-9$ are represented by adding dot 6 to the letters a-i ( $\because 1,: \vdots 2$, $\because: 3, \ldots)$ and the digit 0 is represented by $:$. In other words, while inkprint has only one set of symbols for Arabic numerals, braille has at least three sets of symbols, all of which are incompatible and mutually-unintelligible with one another, and which depend on the region of the world and on the genre of text in which they occur. The case of multiple standards for braille numerals provides an important parallel to the current situation with respect to the IPA, which, likewise, has only one universally-recognized set of symbols in print, but has developed multiple, incompatible braille representations in different countries over the years. This situation will be fully explicated below in section 3 .

Currently, the only internationally-recognized braille system is Braille Music Notation (BANA 1997b). All other discipline-specific notations are defined by country-specific braille authorities, and tend to be incompatible with one another. For example, the braille notation for mathematics and science in the United States and Canada (Nemeth 1972) is mutually unintelligible with the braille notation for mathematics and science used in the United Kingdom (BAUK 2005, 2008); the computer braille notation in the United States and Canada (BANA 2000) is different from that used in the United Kingdom (BAUK 2006); and, the central concern of the present article, the braille notation for the IPA in the United States and Canada (BANA 1997a) is incompatible with the braille notation for the IPA recognized in the United Kingdom (BAUK 1990) and much of the rest of the world. In 1991 the International Council on English Braille (ICEB) was formed, and soon began working to unify the disparate braille 
codes in English-speaking countries, as well as working to create a single code to encompass literary, mathematical, and computer notation (see Bogart, Cranmer \& Sullivan 2000 for more details). As part of this work, ICEB also undertook the task of unifying the braille notations of the IPA, the outcome of which is the core of this article. The two aspects of braille that pose the greatest challenge for discipline-specific notation such as the IPA are (i) the limitations imposed by having only 63 braille characters to represent a potentially infinite number of print glyphs (cf. Poole 1982), and (ii) the spatial limitations imposed by the linear nature of braille when representing two-dimensional aspects of print such as combining diacritics and modifiers. I will return to the specifics of how these issues have been addressed in IPA Braille in sections 4.2 and 4.3 below.

\section{History of braille notations for the IPA}

During the past several decades, the situation with respect to braille and the IPA has become chaotic and confusing, marked by the existence of several incompatible (i.e. mutually unintelligible) braille IPA systems. It is ironic that the INTERNATIONAL Phonetic Alphabet (author's emphasis) has not at all been international for braille readers. The aims of the present section are to survey, comment on, and provide a detailed comparison among the prior sources for braille IPA. This exhaustive comparison clearly shows the vast incompatibilities between these existing systems, and, in some cases, illustrates ways in which previous braille IPA notations have violated the principles of the IPA itself. This comparison sets the stage for the remainder of the article, which presents IPA Braille (Englebretson 2008) as a solution to the current problem of disparate notational systems, and as a robust and up-to-date braille IPA now available for use by students and professionals.

The Handbook of the International Phonetic Association (IPA 1999: 32) lists three references for braille notations of the IPA: Merrick \& Potthoff 1934 (the publication date is incorrectly listed in the Handbook as 1932), AAWB 1977 (based on Merrick \& Potthoff 1934), and BANA 1997a (which is a completely different notation, not compatible with the other two). In addition to the references listed in the Handbook, Wells-Jensen (2005) cites a fourth source, BAUK 1990, which is also based on Merrick \& Potthoff 1934. UNESCO 1990 provides yet a fifth source of braille symbols for representing IPA sounds, which is compatible with neither the Merrick \& Potthoff (1934) notation and its offshoots, nor with the BANA 1997a notation. In addition to these five sources, braille authorities in non-English-speaking countries may have developed their own systems for representing the IPA, although none have contacted me in response to my LinguistList query, JIPA announcement, or ICEB activities.

The earliest attested braille representation of the IPA is Merrick \& Potthoff (1934), which was published in London by the organization now called RNIB (Royal National Institute of Blind People). It was developed based on the IPA charts revised to 1932, and benefited from extensive input from, and close consultation with, Daniel Jones at University College London. In the present author's view, the 1934 publication is a paragon of what a braille code should be: it is completely faithful to the print IPA of the time, is linguistically-informed, and is a highly systematic and comprehensive braille representation of the IPA. The booklet contains a list of all of the braille symbols used for representing the consonants and vowels of the IPA (revised to 1932), and symbols for length, stress, tones, and diacritics. The list also includes raised-line drawings of the inkprint glyphs for each braille symbol. These lists are followed by pages of articulatory descriptions and example words to illustrate each IPA sound, and subsequently by a section of text illustrations (transcriptions of 'The North Wind and the Sun' passage) in Italian, French, Spanish, English, German, Hungarian, Arabic, and Chinese. The publication concludes with braille versions of the consonant and vowel charts arranged in the traditional IPA row-and-column format. This book was re-issued by RNIB in 1948 , with the addition of a brief appendix of notes and corrections to the earlier version. This 
publication has long been out of print, and, except for copies in private braille collections (one of which was donated to the present author), the original English version is no longer publicly available. As of late 2007, the listing for this title has been removed from the catalog of the braille collection at the Library of Congress in the United States (National Library Service for the Blind and Physically Handicapped) since the book is no longer in their collection, and as of the writing of this article, it is likewise no longer obtainable from braille lending libraries in other English-speaking countries either. However, German and French translations still exist; the German version, dated 1938, is available from the Deutsche Blindenstudienanstalt in Marburg, and the French version, dated 1982, is available from Groupement des Intellectuels Aveugles ou Amblyopes in Paris. As in the English original, neither version contains IPA symbols introduced or modified after 1932, and thus are 73 years out of date from the 2005 revision of the IPA.

The Merrick \& Potthoff notation starts from the observation that the IPA is based on letters in the Roman alphabet; 25 of the 26 braille IPA symbols are identical to those in the braille Roman alphabet as presented above in table 1 . The one exception to this is the letter : c; where IPA has [c], the Merrick \& Potthoff braille notation uses $: \because: \because$, and uses $\because:$ (plain c) to represent IPA [c]]. No explanation is given for this exception. Twenty of the IPA consonant and vowel symbols not found in the Roman alphabet are represented by single-cell braille characters, such as $\because:\left[\int\right], \because[\mathrm{y}]$, and $\because:$ [ə]. In general, these 20 one-cell symbols appear to have been chosen to represent the sounds that figure prominently in the transcription of English and other European languages, for the primary cardinal vowels, and for sounds which are typologically frequent. The remaining IPA symbols (typically those for sounds that are typologically rarer) are composite braille characters, in which a sequence of two braille cells represents one print IPA glyph. Each of these composite characters begins with a prefix of $\because, \because,: \because, \because: \because, \because$, , and.. . These prefixes are used semi-systematically to indicate particular features of a base glyph, e.g. the prefix $\because:$ is generally used to indicate retroflex sounds written with a right-tail in print ( $\because:$ [t], $\because \because$ [d], $\because \because:$ [n], etc.), the prefix $\because \because$ is generally used for small-capital glyphs $(\because \because \mathrm{G}], \because \because[\mathrm{N}], \because:$ [R], etc), and the prefix $\because$ is commonly used for barred vowels (e.g. $\because \therefore[\mathrm{i}], \therefore \therefore[\mathrm{u}], \therefore \because[\theta]$ ). Diacritics are composed similarly, and are placed before or after (depending on the specific diacritic) the base characters which they modify, e.g. the sequence $: .$. before a letter indicates an umlaut above that letter: $: . .: \vdots$ : [ö]. However, due to the vast array of print glyph types, and the rather limited resources of these seven braille prefixes, there is a good deal of arbitrariness inherent in the Merrick \& Potthoff system - and, for that matter, in any braille representation of the IPA, due to the way in which braille characters are composed. (Although see Gray 2006 for an attempted modification of the Merrick \& Potthoff notation to increase its overall systematicity.) The Merrick \& Potthoff notation served as the basis for the braille IPA systems used in Germany, France, and most English-speaking countries throughout the 20th century. Unfortunately, however, it has never been updated to keep pace with the inkprint IPA - and it is therefore 73 years out of sync with the 2005 revision of the IPA.

BAUK (1990) is a direct descendent of the Merrick \& Potthoff system. It is essentially a re-issue of the original Merrick \& Potthoff code as applied to the 1979 IPA, reformatted and retyped, minus the illustrations, texts, and explanations given in the 1934 booklet. It is crucial to point out, however, that although this was published in 1990 and based on the 1979 IPA chart, it is by no means an update to the braille IPA: the only braille symbols that are given are those found on the 1932 inkprint charts themselves. In other words, where the 1979 IPA chart shows a symbol that was not used in 1932, BAUK 1990 shows its braille equivalent as a blank (.... series of two braille dashes). It is also noteworthy that this publication contains several typos, at least two of which cause it to be incompatible with the IPA's principle of one symbol per sound: in two instances, BAUK 1990 shows the same braille symbol for different print glyphs. These errors are not found in the original 1934 version, leading the present author to suspect that they were accidentally introduced through typing errors when the 1990 publication was created. For example, braille :: t is shown (1990: 2) correctly as the 
symbol for IPA [t], but this same symbol : is also shown (1990: 7) incorrectly for IPA [ $\phi$; the actual Merrick \& Potthoff (1934: 18 and 37) braille for $[\phi]$ is ::. In other words, BAUK (1990) gives : $:$ for both [t] and [ $\phi]$, creating a situation in which braille IPA users can no longer distinguish between these two print glyphs. Similarly, BAUK (1990: 8) lists :: as the symbol for [ $\mathrm{v}$, which is the same as the symbol given for [u] (1990: 4). Merrick \& Potthoff

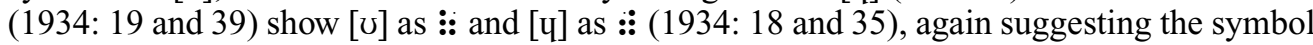
was miscopied in BAUK 1990. Additionally, BAUK 1990 contains several inaccuracies in the typographic descriptions of the characters, e.g. among others, calling [3] 'zeta' - an error also not present in the original Merrick \& Potthoff publication. The blanks in the chart for post-1932 glyphs, the typos causing the unacceptable one-to-many braille to print mappings, and the inaccurate typographic descriptions make this a difficult and frustrating source for students and professionals needing a braille representation of the IPA. However, these problems notwithstanding, BAUK 1990 has been the official braille IPA notation used in the United Kingdom since 1990.

Another offshoot of the Merrick \& Potthoff (1934) system is found in Rule XIX, Section 45 of AAWB 1977 (see IPA 1999: 32). AAWB 1977 was, until the mid-1990s, the manual used by print-to-braille transcribers in the United States and Canada; it is now obsolete, however, and no longer in print. Rule XIX, Section 45 delineates the methods and symbols used in the print-to-braille transcription of phonetic and phonemic material including IPA. This section incorporates the braille symbols from Merrick \& Potthoff (1934) in their entirety, but does not include the raised-line drawings of the print glyphs, the examples and discussion, nor the sample texts. However, it does provide more detailed typographic descriptions of the glyphs than are found in the original. The glyphs presented in this 1977 publication include only those found in the IPA revised to 1932; in other words, as with BAUK 1990, no symbols are given for glyphs added or revised after 1932. It does, however, include a brief overview of braille symbols for 'r-colored vowels' and other 'colored' sounds (AAWB 1977: 112) not shown in Merrick \& Potthoff. The only inconsistency between this source and the original is the braille

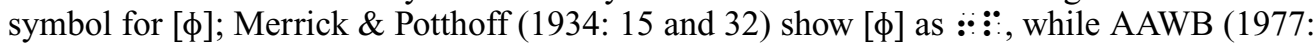
110) shows it as $: \because$. No explanation is given for this change, although a note in Merrick \& Potthoff does seem to suggest $: \because$ is a possible variant of $: \because:$; $: \because$ is the symbol used for $[\phi]$ by the International Institute of African Languages and Culture' (1934: 42). In general, AAWB 1977 was an excellent source and a faithful reproduction of the original Merrick \& Potthoff notation - although the lack of IPA glyphs introduced or modified after 1932 has posed a serious problem. However, this manual is no longer used, is out of print, and has been obsolete since the mid 1990s.

The successor to Rule XIX, Section 45 of AAWB 1977 is Rule 18 of BANA 1997a, which is also listed in the IPA Handbook (1999: 32). This is the official braille IPA notation recognized in the United States and Canada since 1997. It is the only notation to incorporate the 1989 updates to the IPA (although post-1989 revisions are not included). However, it is a radical departure from the Merrick \& Potthoff (1934) system, and is mutually unintelligible with the braille IPA currently used in the United Kingdom (BAUK 1990) and the IPA braille systems used in France and Germany. As such, this system also marks a departure from the braille IPA notation used in the United States and Canada prior to 1997, but no justification is provided for taking this seemingly hasty step. Braille-reading linguists and phoneticians appear not to have been consulted in the development of BANA 1997a; rather, the braillists who developed it seem to have worked solely on the basis of the visual appearance of the print glyphs, without considering their meaning or use. The BANA 1997a IPA notation uses the 26 letters of the Roman alphabet to represent the equivalent consonant and vowel symbols of the IPA. Nine additional one-cell symbols are used to represent various other IPA consonants. However, except for [3], which is :: in both systems, these one-cell symbols have completely different IPA meanings in BANA 1997a than they do in the original Merrick \& Potthoff (1934) notation. Table 2 lists the nine one-cell symbols of BANA 1997a, along with their original meanings in the Merrick \& Potthoff notation. 
Table 2 Single-cell symbols in BANA (1997a), contrasted with their original meanings in Merrick \& Potthoff (1934).

\begin{tabular}{|c|c|c|c|c|c|c|c|c|c|}
\hline Braille & $\therefore:$ & $\ddot{\vdots}$ & $::$ & $\because$ & $\ddot{\because}$ & $\vdots$ & $\vdots:$ & $\because:$ & $::$ \\
\hline Merrick \& Potthoff 1934 & 3 & $\eta$ & ð & $œ$ & $æ$ & $\varepsilon$ & כ & $\varnothing$ & $\mathrm{n}$ \\
\hline BANA 1997a & 3 & ð & $\eta$ & $\odot$ & $\int$ & $?$ & S & | & $!$ \\
\hline
\end{tabular}

Table 3 Examples of IPA Glyphs originally represented by single-cell symbols in Merrick \& Potthoff (1934), now represented by multi-cell composite symbols in BANA (1997a).

\begin{tabular}{|c|c|c|c|c|c|}
\hline $\mathrm{IPA}$ & $æ$ & $a$ & o & ə & $\varepsilon$ \\
\hline Merrick \& Potthoff 1934 & $\ddot{\because}$ & $\because$ & $\vdots \vdots$ & $\because$ & $::$ \\
\hline BANA 1997a & $\because \ddot{\vdots}:$ & 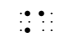 & $\because \because$ & $\because \vdots$ & $:: \because$ \\
\hline
\end{tabular}

No justification is provided for the reassignment of these symbols, nor any reasons for using one-cell symbols to represent typologically infrequent glyphs such as the three clicks and the voiced pharyngeal as listed in table 2 . For all of the remaining consonants, vowels, and diacritics, BANA 1997a uses two- or three-cell composite symbols, again assigning them different meanings from the Merrick \& Potthoff notation. Table 3 gives a few examples.

Again, BANA 1997a provides no reason for adopting a new notation for the IPA different from the Merrick \& Potthoff system, and no explanation why this system might be more effective or desirable. Essentially, BANA 1997a has taken one set of arbitrary symbols and simply replaced them with a new set of arbitrary symbols. From a usability perspective, BANA 1997a is inferior to the Merrick \& Potthoff system for two reasons: it is less economical, and it is phonetically misleading. It is less economical in the sense that its greater use of multicell composite symbols causes it to take more space on the page and makes it slower to write; this is a distinct disadvantage for field, clinical, and classroom settings where speed is an important consideration. For example, as illustrated in the above table, [æ] consists of the one-cell symbol $\because:$ in Merrick \& Potthoff 1934, but in BANA 1997a has been replaced with the three-cell composite symbol $: \because \because$ (literally a + e), which takes three times as much space and three times longer to write than the original one-cell symbol. Secondly, while this three-cell composite symbol may attempt to capture the visual appearance of the print glyph, it is misleading from a phonetic perspective, since [æ] is in no way the summation of $[\mathrm{a}]+[\mathrm{e}]$ as the three braille cells seem to indicate; similar observations can be made for the representation of [0] in this system as $\because \because$ (a modified c) rather than either as a modified o or as the single-cell symbol $:$ as in Merrick \& Potthoff 1934 . While this section cannot provide a full critique of the braille IPA system given in BANA 1997a, it is fair to say that it has not been at all well-received by braille-reading linguists in the United States and Canada. I do not recommend it to students or colleagues, and Wells-Jensen (2005) does not cite it in her $J I P A$ article on blind students in the phonetics classroom, choosing instead to recommend the British system in BAUK 1990.

Another source for braille representations of the sounds of the IPA is shown in UNESCO (1990: 3-7). I mention it here only in passing, because it is not specifically designed as a way of representing IPA per se, but rather is intended for use in developing braille orthographies for languages which do not currently have a braille alphabet. (However, as a working linguist, I would question its suitability for this purpose, since a non-judicious use of these symbols would simply impose the phonemic system of English onto the target language.) This system frequently assigns one braille symbol to represent a variety of IPA sounds. For example, (lowercase a) is shown as the braille equivalent for [a], [æ], [ə], and [e]. Since this notation cannot represent each IPA glyph uniquely, it will not be discussed further here and should not be considered a viable alternative.

In sum (excluding sources no longer in print), there are currently two viable systems for representing the IPA in braille: BAUK 1990 and BANA 1997a. As discussed above, both sources are problematic. BAUK (1990) does not contain any post-1932 IPA symbols, and also 
contains a number of typos and inaccuracies. BANA 1997a contains braille representations of the symbols of the IPA as revised to 1989, but is an inefficient braille system and is not robust enough to be used in many professional capacities. The existence of two, mutuallyunintelligible and out-of-date braille IPA systems has posed a serious problem for braillereading students needing to learn the IPA, for braille-reading professionals who use the IPA for their work, and for print-to-braille transcribers wishing to produce braille editions of current linguistics or phonetics textbooks. As a result of this situation, most of us in the field have generally improvised our own braille IPA systems unique to our specific purposes (cf. Gray 2006). Improvised braille IPA notations are suitable for one's own fieldwork notes, class lecture notes, and writings that will not be read by others, but the lack of a standard, international braille IPA makes it virtually impossible to share materials, since each user tends to have innovated an idiosyncratic set of symbols. Furthermore, machine-readable and computer-produced braille IPA materials have previously been unworkable, since there has been no standard and complete set of symbols to include in print-to-braille translation tables.

\section{IPA Braille}

To resolve the longstanding problems of incompatible and out-of-date braille notations for the IPA as discussed in the previous section, IPA Braille (Englebretson 2008) provides a fully updated notation, with braille equivalents for all symbols of the IPA as revised to 2005 . The complete IPA Braille charts are given in the appendix to the present article, and will be referred to throughout this section. These charts are presented here for ease of reference, for the convenience of readers who may wish to refer to them when interacting with braillereading students, and for anyone else interested in the development of braille and/or the documentation of alternative representations of the IPA. The current section begins with an overview of the development of IPA Braille and the trial period during which it was piloted (section 4.1), discusses the rationale and considerations taken into account in developing IPA Braille (section 4.2), presents specific details about the IPA Braille symbols themselves (section 4.3), and concludes with a general overview and outline of the IPA Braille publication (section 4.4).

\subsection{Development and trial period}

The International Council on English Braille (ICEB) was formed in 1991, in order to work toward the unification of the various braille codes used in English-speaking countries around the world. In 1999, a resolution was passed at the ICEB General Assembly calling for the development of a unified braille representation of the IPA. This proposal was put on hold until early 2005, at which point the present author was invited to begin work on this project under the auspices of the ICEB Committee on linguistics and foreign languages. In September 2005, I presented a working draft of IPA Braille to the Committee for corrections and comments, after which point a period of public discussion began. (See e.g. the announcement and call for input posted on LinguistList 16.3138: http://linguistlist.org/issues/16/16-3138.html, as well as the project announcement in 2006 in the IPA News section of JIPA 36(1), page 133.)

Beginning in October 2005, PDF and braille files were made publicly available on the web, followed by a production run of 24 embossed braille copies that were mailed to individuals who had requested them and who were subsequently invited to offer feedback. Copies were sent to braille readers in all ICEB member countries: the United States, Canada, the UK, Australia, New Zealand, South Africa, and Nigeria. During the subsequent two years, we received comments on both the web-based and hardcopy files from individuals with varying levels of experience with both braille and phonetics. These comments were overwhelmingly positive, and the suggested changes focused primarily on formatting issues, the addition of missing Unicode numbers, correction of inconsistently-ordered articulatory descriptions, and incorrect braille dot numbers. 
A second group of readers to closely examine IPA Braille consisted of professional printto-braille transcribers and representatives of country-specific braille authorities. Comments from this group of readers led to the inclusion in the IPA Braille publication (Englebretson 2008) of substantial narrative detail contextualizing IPA Braille, a general overview of articulatory phonetics, and an index listing IPA symbols and their braille equivalents in pseudo-alphabetical order. These additions were designed for the benefit of beginning students as well as print-to-braille transcribers who are not themselves familiar with the IPA.

IPA Braille was also piloted in the classroom with three blind students in introductory linguistics courses: one at University of California Santa Barbara, one at University of California Berkeley, and one in the author's own course at Rice University. Feedback from the students, Teaching Assistants, or course instructors all indicated that IPA Braille had proven to be equivalent to the inkprint IPA in terms of learnability and function. Students further expressed appreciation for the raised drawings of the inkprint IPA symbols alongside their braille equivalents. No changes were recommended based on this pilot.

Finally, in order to confirm the viability of IPA Braille and it's compatibility with automated print-to-braille translation, I converted 16 of the sample 'North Wind and the Sun' passages from the IPA Handbook (IPA 1999) into braille. Five of these passages (American English narrow transcription, Hong Kong Cantonese, Croatian, French, and Portuguese) appear in the appendix to the IPA Braille publication (Englebretson 2008), by permission of Cambridge University Press. These passages illustrate IPA Braille in use, and demonstrate that it is indeed a robust notation, fully capable of accurately representing all facets of the inkprint IPA.

In August 2007, I submitted a final report on IPA Braille (including comments and recommendation letters from users) to the ICEB Executive Committee, which subsequently voted unanimously in favor of its adoption. Based on the overwhelmingly positive responses collected during the trial period, IPA Braille appears to be easy to learn and viable for a broad base of users in all contexts where the inkprint IPA is likewise relevant.

\subsection{Design rationale}

The current section outlines the principles around which IPA Braille has been designed. These have roughly to do with the overlapping concerns of accuracy, user friendliness, flexibility, and computability.

First and foremost, in terms of accuracy, IPA Braille is completely faithful to the inkprint IPA; i.e. every glyph has a unique and unambiguous braille equivalent. This is not a trivial undertaking, given that braille has only 63 unique symbols, while the 2005 revision of the IPA comprises around 180 glyphs (including consonants, vowels, diacritics, modifiers, and enclosure symbols). In other words, the number of IPA glyphs is nearly three times the number of single-cell braille symbols, and a direct mapping of one IPA glyph per braille cell is simply not possible. For this reason, most IPA glyphs must be represented in braille as composite characters - consisting of two or more braille cells. IPA Braille was carefully designed based on a system of root (or prefix plus root) symbols for consonants and vowels, and an unambiguous, clearly-delineated method for the formation of diacritics and other modifiers. These principles will be further explained in section 4.3 below - consult the appendix for the full charts.

To facilitate overall learnability, IPA Braille is based as far as practical on an alreadyexisting braille system, so that users can avoid relearning symbols whenever possible. Because of the international nature of the Merrick \& Potthoff (1934) notation, and because many braille-reading linguists are already familiar with it, a slightly modified version of this notation was chosen for the consonants and vowels of IPA Braille. However, the braille diacritics and modifiers had to be completely reworked, both because of changes in inkprint usage since the 1932 IPA revision on which the original Merrick \& Potthoff notation was based, and also to bring them in parallel with the composition of combining diacritics in Unicode. See sections 4.3.2 and 4.3.3 below for specific details of IPA Braille diacritics and modifiers. The general speed and economy of the Merrick \& Potthoff notation provides another reason why it was 
chosen as the basis for IPA Braille, maintaining the principle of using one-cell symbols for more-frequent glyphs, and multi-cell composite symbols for glyphs which are typologically less-frequent and less canonical. (Of course issues of frequency and markedness are not always clear-cut, and IPA Braille largely relies on the Merrick \& Potthoff notation for this determination.)

IPA Braille is intended to be as fast and economical as the inkprint IPA. In other words, a blind person using braille IPA in a classroom or field setting should not require significantly more time, effort, or expense than a sighted person doing the same tasks in similar environments. The inkprint IPA is relatively independent of technology; i.e. a sighted user of the IPA does not need to be bound to a computer, but can write it using tools as simple as pencil and paper. IPA Braille is similarly technology independent: a blind user can write it using tools as cheap and simple as the braille slate and stylus (the equivalent of pencil and paper for braille writing), or as sophisticated as a braille PDA or a standard personal computer running adaptive software and a braille embosser. This flexibility ensures that IPA Braille can be used in as wide a variety of contexts as possible. IPA Braille is designed to be adequate and robust enough to meet the needs of those of us who use it regularly - not only for students and professionals in the language sciences who generally have access to specialized equipment, but also for language learners in developing countries where expensive adaptive technology such as braille displays and embossers is far less prevalent. For example, the Nigerian representative to ICEB (who is also the chair of the ICEB committee on linguistics and foreign languages under whose auspices IPA Braille was developed) has used IPA Braille to transcribe passages of IPA text used in pronunciation guides in her students' ESL textbooks.

One of the questions that has regularly come up regarding IPA Braille (usually from sighted people who do not read braille tactually) concerns the decision to use the standard six-dot braille cell, rather than the eight-dot (2 columns of four dots each) system developed in the 1970s for computer displays. Since an eight-dot braille cell allows for the representation of 256 unique characters, it would logically seem to be a better choice, enabling each IPA glyph to be represented by a single braille cell. However, there are at least two significant factors militating against the use of a nonstandard eight-dot cell for IPA Braille. First, many braille readers find eight-dot braille difficult to read - both because of habituation to a six-dot cell, and also due to the increased size of an eight-dot cell relative to the ball of the fingertip. In order to feel the entire vertical length of an eight-dot cell, most braille readers have to 'scrub' (i.e. rapidly move the fingertips up and down over the larger characters) a movement which disrupts the fluid lateral motion necessary for efficient braille reading. Secondly, not all braille embossers and displays allow for eight-dot braille, and it cannot be written at all using a slate and stylus, which is a disadvantage for users in field settings or developing countries with limited access to technology. Therefore, so that it is accessible to the widest possible group of users and is embossable using all types of braille technology, IPA Braille uses the standard six-dot braille cell.

Finally, IPA Braille readily lends itself to automated braille translation, so that any machine-readable Unicode file can be converted into braille, and, vice versa, any braille IPA material can be converted into print. This is especially useful in classroom situations to facilitate exchange of materials among blind and sighted users of the IPA. For this reason, the IPA Braille tables include Unicode numbers for each glyph. Makers of automated braille translation software are now able to include translation tables in their products to enable the conversion between Unicode IPA data and IPA Braille. As of the writing of this article, current versions of commercial braille translation software do not yet offer built-in support for IPA Braille - although users of some of these products can achieve this by modifying the Unicode tables directly, and future out-of-the-box support would be trivial for software makers to implement. Even without professional braille translation software, however, anyone with a background in Perl (or any programming language capable of transforming text strings in a rule-ordered manner), can write an algorithm to convert Unicode IPA texts into braille, or, vice versa, to convert IPA Braille texts into Unicode. The five sample passages from the IPA 
Handbook were prepared for the braille publication in exactly this fashion: Unicode data were transformed to IPA Braille with only minimal user intervention. Similarly, any Unicode-aware screen reader can now be modified to allow blind users to read IPA directly on a standard computer using a speech synthesizer or braille display. (For specific details, e-mail the author at the address provided at the beginning of this article.)

\subsection{The symbols of IPA Braille}

This section gives a basic overview of the construction of IPA Braille symbols and factors related to braille usage.

\subsubsection{Consonants and vowels}

As discussed in section 4.2, in order to promote continuity and learnability, the consonant and vowel symbols of IPA Braille are based primarily on the Merrick \& Potthoff (1934) notation. However, a number of modifications to this system were necessary: (i) to accommodate new glyphs not appearing in the 1932 IPA on which the Merrick \& Potthoff notation was based, (ii) to take into account changes in both IPA usage and braille usage during the past eight decades, and (iii) to maintain overall consistency among IPA Braille glyphs whenever possible. The 26 Roman letters in the IPA are represented in IPA Braille by their standard braille equivalents. (See table 1 in section 2 for the Roman alphabet in braille, and the appendix for the full consonant and vowel charts.) In terms of divergence from the Merrick \& Potthoff notation, this now means that $::$ (braille letter c) represents [c] as expected, and no longer [c], which is now $: \because:$ in IPA Braille. The IPA consonants symbolized by the Greek letters $[\phi \beta \theta \gamma$ $\chi]$ have been updated to reflect the internationally-recognized braille symbols for Greek letters

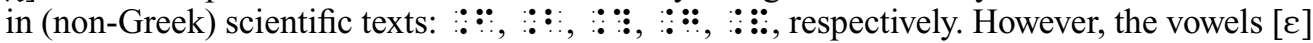
and $[v]$ continue to be represented by the single-cell symbols $\therefore$ and $::$, respectively, in order to maintain consistency with the Merrick \& Potthoff single-cell vowel symbols, and because these IPA glyphs appear in the Latin (not the Greek) portion of the Unicode codeblock. Other noteworthy changes include the representations of $[K]$ and $[4]$, formerly :: and :: in Merrick \& Potthoff, now represented as :: : and $: \because$ in IPA Braille. This allows $::$ to serve as the new prefix for all clicks, frees up :: to be one of three undefined single-cell symbols (along with $\because:$ and :: ) available for use in future expansions of Braille IPA (see section 5), and indicates to braille readers that the roots of these symbols are the glyphs :: and :: (Roman letters y and $h$ ).

Although the mapping of braille symbols to IPA glyphs is essentially arbitrary (i.e. there are very few systematic features of braille symbols that can be said to correspond directly to features of print glyphs), there are some patterns which can be helpful for IPA Braille learners. For example, three pairs of IPA Braille consonants are mirror images of one another, which can serve as a mnemonic device: $: \because$ and $\because:\left([\mathrm{s}]\right.$ and $\left.\left[\int\right]\right), \because$ and $: \because$ ([z] and [3]), $\because:$ and $\because:$ ([n] and [n]. Similarly, the front and back open-mid vowel pair $\vdots$ and $\vdots:([\varepsilon]$ and [o]) are also mirror images. Although not completely systematic, a number of the prefixes in multi-cell composite symbols can also be learned in groups: all of the retroflex consonants written with a right-tail

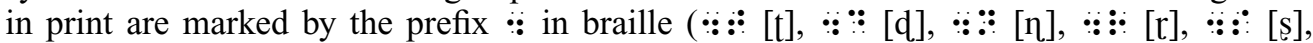

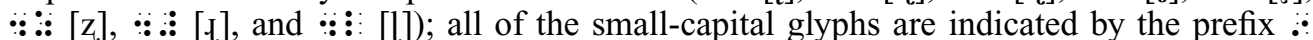
$(\because \because[\mathrm{G}], \because \because \mathrm{H}], \because \vdots[\mathrm{B}], \because \because[\mathrm{R}], \because \vdots[\mathrm{b}], \because \vdots[\mathrm{L}], \because \because[\mathrm{H}], \because \because[\mathrm{E}]$, and $\because \because[\mathrm{Y}]) ;$ all implosives

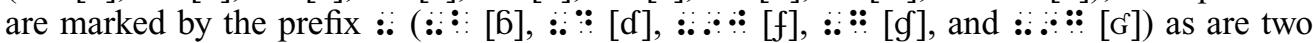

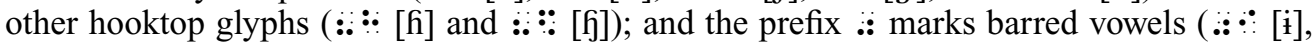
$\therefore \because[\mathrm{u}]$, and $\because \because[\Theta])$. Because the IPA glyphs for clicks have been substantially revised since the 1932 chart, the IPA Braille symbols for clicks have likewise been updated. :: is now used

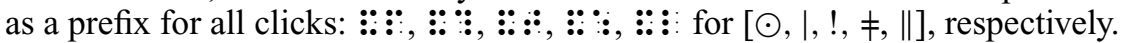

However, while these regularities may indeed serve as helpful mnemonic devices, it is crucial to emphasize that a fully systematic one-to-one mapping between braille prefixes and print glyph types is not possible in IPA Braille. This is true primarily because there are greater numbers of print modifications to glyphs than there are available braille prefixes to represent them. Thus, while $\because$ generally indicates small-capital glyphs as shown above, it has also been 
'co-opted' on $\therefore:$ : [千] and $\therefore:$ [于]; while :: generally indicates retroflex consonants written with a right-hook, it has also been used for $\because \because[\mathrm{\varphi}]$; and while $::$ often indicates an implosive

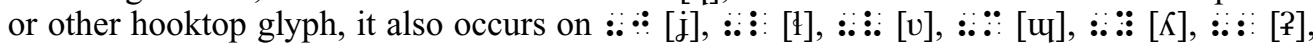

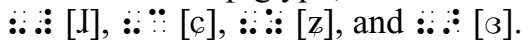

Ultimately, IPA Braille must be memorized in exactly the same way as the inkprint IPA by associating each glyph directly with the specific sound it represents and/or its articulatory description (rather than, for instance, attempting to learn IPA Braille by associating the braille patterns with the names of inkprint glyphs - a practice which this author recommends against). Once students have fully associated each IPA Braille pattern with its specific IPA sound, any correspondence or lack of correspondence between braille prefixes and print glyph shapes becomes irrelevant. Based on feedback during the trial period, students learning IPA Braille have not faced any substantial difficulties different from those which learners of the inkprint IPA generally experience.

\subsubsection{Diacritics}

The most drastic difference between IPA Braille and the Merrick \& Potthoff notation is in the system of diacritics and modifiers. These have been completely overhauled, due primarily to the changes in IPA diacritic usage since 1932. The IPA Braille representation of diacritics is now far more information-rich and systematic than it was previously, especially with respect to the placement of the inkprint glyphs. It is also in parallel with the composition of combining diacritics in Unicode. (For more information on the specific characteristics of Unicode combining diacritics, consult the documentation available from the Unicode Consortium at http://www.unicode.org.) As mentioned in section 2 above, one of the challenges of braille pertains to the necessity to represent two-dimensional inkprint data in strictly linear form. In other words, unlike in print, it is physically impossible in braille to position symbols superscript or subscript to one another, since a line of braille is always uniformly three dots high, and there is no space above or below the line as there is in print. With respect to the IPA, this means that a braille diacritic cannot physically be placed above or below a base glyph as it is in print. This has been addressed in IPA Braille by specifying that combining diacritics must always come immediately after the glyph being modified, and by providing clear indicators as to the placement of the inkprint diacritic. For example, [a] would be written $::-$ - the letter a $: \because$ followed by the composite symbol $: \because$ for the voiceless diacritic occurring below the inkprint glyph. These kinds of linear solutions for representing two-dimensional layouts are quite familiar to braille readers, as similar strategies are used in Braille Music Notation (BANA 1997b) and in the various systems available for braille mathematics and science (Nemeth 1972; BAUK 2005, 2008).

All IPA Braille combining diacritics are defined as composite symbols, beginning with a placement indicator: $: \because$ (dot 4$)$ indicates that the diacritic appears above the base glyph either directly above, or superscript after. :. (dot 6) indicates that the diacritic appears below the base glyph - either directly beneath, or subscript after : (dot 5) indicates that the diacritic is on the same level as the base glyph - either superimposed through the center of the glyph, or immediately after it. For example, in IPA Braille, the $\sim$ diacritic is written as $: \because:$ : $: \because:$, or $: \vdots:$, depending on its position with respect to the base character: e.g. [ã] $:: \because::$ for nasalization, [€] :: :: for velarization/pharyngealization, or [a] :: :: for creaky voice.

Because there are only three same-level IPA diacritics ( $\because: \because$ 'superimposed tilde' to indicate velarization/pharyngealization, :: 'right-hook' to indicate rhoticity, and : $:$ : 'apostrophe' to indicate an ejective), $\because$ also indicates the inkprint tie bar or ligature, and is placed between the two base glyphs which are tied or ligatured together, e.g. : $::$ : [ kp].

Note that IPA Braille diacritics are explicitly defined as multi-cell, composite characters, including the placement indicator. This is crucial for two reasons. First, as just discussed, the initial dot clearly shows the vertical position with respect to the base glyph. Secondly, the initial placement dot clearly indicates that the braille symbol represents a combining diacritic, rather than a consonant or vowel that may happen to have the same IPA Braille dot configuration. An astute reader may have already noticed, for instance, that the IPA 
Braille symbols :: [n] and :: [ð] are homologous to :: (ring below) and :: respectively, and it is the initial placement dot that 'shifts' the meaning of the symbol to a diacritic rather than a base glyph. This is true of many diacritic symbols (see the appendix), whose dot configurations may indicate a consonant or vowel if not preceded by a diacritic placement dot.

For purposes of consistency, the roots of many of the IPA Braille combining diacritics are identical to those defined in Unified English Braille (UEB), specifically the UEB symbols $\therefore$ 'acute accent', :: 'grave accent', :: 'tilde', $\because$ 'umlaut', $\because:$ 'circumflex', and :: 'circle'. However, unlike their UEB counterparts, in IPA Braille the combining diacritic always comes after the glyph that it modifies, and always includes the IPA Braille placement dot to indicate its position relative to the base glyph as described above.

When a base glyph combines with two or more diacritics, IPA Braille transcribes them in order from lowest to highest level, followed by any non-combining modifiers. For example, the IPA segment [ $\hat{r}:]$ (as seen in the Croatian transcription in IPA 1999: 69) would be transcribed in IPA Braille as $: 0: \because$ : beginning with the base glyph $: \because \mathrm{r}]$, followed by the bottommost combining diacritic : $:$ (the syllabic mark below), moving upward to the top-most combining diacritic $: \because$ (the circumflex above), and then followed by the non-combining modifier $\because$ (long).

\subsubsection{Other modifiers}

Non-combining modifiers (i.e. those that do not occur attached to a base glyph, such as the tone letters, arrows, and symbols for stress and phrasing) are all indicated by a prefix of :: (dots 456) in IPA Braille. (The length modifiers $\because:$ and $\because \because \cdot$ are the only exceptions.) Most of these symbols are new to IPA Braille, as they did not exist in the original Merrick \& Potthoff notation. These symbols were designed to be as iconic as possible with respect to the print glyphs. For example, the IPA Braille tone letters mimic the shape of the print tone letters (although the 'stem' is on the left in IPA Braille to maintain the : prefix for modifiers): : : : $:$,

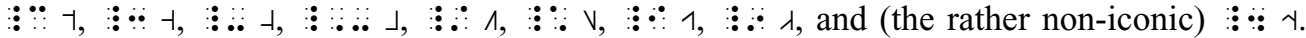
Similarly, the upstep and downstep arrows $:: \because{ }^{\uparrow}$ and $:::^{\downarrow} \downarrow$ have also attempted to capture the iconic nature of the print symbols, where the triangle of dots in the corner of the cell represents an upward or downward arrow head, and the dot in the other corner depicts the arrow's tail. Similarly, the dot configurations $: \because: \nearrow$ and $: \vdots \searrow$ reflect a diagonally-pointing arrow. While these braille iconic shapes are by no means perfect (six dots can only hint at a shape, and cannot fully instantiate it), these symbols are designed to reflect the shape of the print glyphs as much as possible.

\subsubsection{Miscellaneous notes on braille usage}

IPA Braille also provides symbols for the inkprint phonetic and phonemic enclosures: : :: [, : : : ] and $: \because: \because$. These symbols also indicate that material is to be read in IPA Braille, rather than the native braille code of the document (e.g. Unified English Braille, English Braille American Edition, French Braille, etc.). IPA Braille also includes ten transcriber-defined 'wildcard' symbols that may be used on a document-specific basis to represent phonetic symbols that are not official IPA glyphs. Finally, IPA Braille allows a means of temporarily switching to another braille code to incorporate symbols such as digits and uppercase letters. See the full publication for further details on these conventions.

\subsection{The IPA Braille publication}

The official IPA Braille publication (Englebretson 2008) is available as a print booklet, as a two-volume braille edition (produced by the Canadian National Institute for the Blind), and as PDF and embossable braille files from the ICEB web site at http:/www.iceb.org/icebipa.htm. (The IPA Braille charts themselves, in traditional IPA format, have been compiled from the publication and are given in the appendix to the present article.) The first volume of the 
braille edition contains a basic introduction and overview of the IPA and the braille symbols used for representing it. In addition to listing the braille equivalent for each symbol in the IPA revised to 2005, this volume offers braille readers an accessible introduction to standard typographic and articulatory phonetic terminology, in order to facilitate clear communication between blind and sighted users of the IPA. The braille tables do not aim to capture the visual layout of the official inkprint IPA chart, which would be opaque to users with little to no background in phonetics, and challenging to format accurately in braille. As Wells-Jensen points out: 'a page large enough to hold eleven columns for place of articulation would have to be approximately two and a half feet across' (Wells-Jensen 2005: 226). Instead, the IPA Braille publication presents the data of each section of the IPA charts in a linear-table format, which is the norm in presenting tabular data in braille that is too large to fit across a single line. In addition to being a familiar and succinct style of presentation to braille readers, the linear table method enables the presentation of all of the data on the inkprint chart in verbal rather than spatial terms, and allows for the addition of typographic descriptions and Unicode values for each symbol - features that are crucial for braille users but which are not present on a traditionally-formatted IPA chart. Unicode values are given for each glyph, which, in conjunction with a Unicode-aware screen reader and keyboard mapping software, readily enable blind individuals to type IPA characters on a standard personal computer without sighted assistance, and to read IPA using a speech synthesizer or braille display. Each table entry comprises seven columns: the inkprint IPA glyph (print version only - tactile drawings of these glyphs are found in the braille Supplement volume), the IPA Braille symbol, the dot numbers of the braille symbol, the Unicode value for the print IPA glyph, the typographic description of the inkprint glyph, the official IPA Number for the glyph, and the meaning or articulatory description of the sound represented by the IPA symbol. For example, the table entry for [ $\mathrm{\eta}]$ appears as follows:

\section{1] :: 1246 U+014B eng 119 voiced velar nasal}

For diacritics and some other modifiers, an additional field in the table entry shows an example of the diacritic combined with a base glyph, in order to illustrate the position of the diacritic in inkprint along with its representation in braille. The tables in appendix 2 of the IPA Handbook (IPA 1999) have served as the primary source for the Unicode values, typographic descriptions, and IPA Numbers, supplemented by information in Pullum \& Ladusaw (1996), the 2005 revision of the IPA chart, and recent updates to the Unicode standard. The volume also contains usage notes unique to braille. Following the main body of the volume and references section is an appendix of five of the sample passages from the IPA Handbook (IPA 1999): American English (narrow transcription), Hong Kong Cantonese, Croatian, French, and Portuguese (all used by permission of Cambridge University Press). These passages illustrate IPA Braille in use, and demonstrate that it is indeed a robust notation, fully capable of accurately representing all facets of the inkprint IPA. The volume concludes with an index providing a list of IPA symbols and their braille representations in pseudo-alphabetical order, as requested by print-to-braille transcribers who are generally not familiar with the IPA, and who thus may find this alternative ordering easier when searching for the braille equivalents for unfamiliar glyphs.

The second braille volume serves as a supplement to the first, presenting tactile drawings of each print IPA glyph along with their braille equivalents. These tactile illustrations enable braille readers to observe and study the shape of each print IPA glyph, and to associate these shapes with their braille representations. Familiarity with the print glyphs is especially crucial for blind students who are learning the IPA in inkprint-oriented classrooms and need to clearly communicate with sighted instructors or colleagues, or to write them using pencil and paper (cf. Wells-Jensen 2005). The supplement is produced separately, so that individuals may download or purchase a hardcopy of either or both volumes, based on their specific needs. In general, a beginning student or someone with no background in phonetics will benefit from the details provided in the introductory volume. On the other hand, an advanced 
student or professional already well-versed in phonetics will not need these details, and will easily be able to learn IPA Braille from the supplement alone. All users will benefit from the side-by-side presentation of raised-print and braille IPA glyphs in the supplement. Its condensed presentation style also makes the supplement an ideal quick reference list of print IPA symbols and their braille equivalents.

\section{Conclusions}

IPA Braille provides a robust solution to the problem of the disparate braille phonetics notations that have previously existed. It is up-to-date, providing clear and unambiguous representations of all symbols of the IPA (revised to 2005). Using a Unicode-compliant screen reader along with synthetic speech or a braille display, blind students and professionals can now access any machine-readable IPA material prepared in Unicode, and can independently type IPA on a personal computer without the need for sighted assistance. Similarly, the automatic conversion of IPA materials to braille, and, conversely, the translation of IPA Braille material into Unicode is now possible. This will greatly simplify the process of converting linguistics and phonetics materials (textbooks, handouts, etc.) into braille for students, and will be useful in sharing materials among blind and sighted users of the IPA.

There are three areas in which IPA Braille needs further development. First, in order for IPA Braille to remain viable, it is essential to keep it updated in tandem with revisions to the (inkprint) IPA. To this end, the present author, in conjunction with the International Council on English Braille, intends to stay apprised of any future IPA revisions, and to incorporate them into IPA Braille shortly after they have been officially adopted in print by the International Phonetic Association.

A second area of future work will be the development of braille equivalents for other systems related to the IPA, such as the extended IPA symbols for disordered speech (IPA 1999: 186-193) and the Voice Quality Symbols (Ball, Esling \& Dickson 1995). There are currently no standard braille notations for these sets of symbols, which is detrimental to blind students and professionals working in clinical fields and related areas. To this end, IPA Braille has plenty of room to incorporate new glyph sets, including three unused single-cell symbols (:: ::, and ::), which can serve as new prefixes for composite braille characters. The present author hopes to collaborate with braille-reading experts in clinical fields, in order to develop a robust system for including extended IPA symbols in IPA Braille.

Thirdly, although IPA Braille is currently officially recognized only by the International Council on English Braille, the author plans to continue advocating for its adoption by additional braille authorities. By so doing, it is hoped that IPA Braille will become the second system of braille notation (after Braille Music Notation) to gain world-wide recognition, in order that braille-reading students and professionals everywhere can have full and equal access to the International Phonetic Alphabet.

\section{Acknowledgements}

For comments on an early version of this manuscript, I wish to thank Katherine Crosswhite, Elizabeth Gentry, and Sheri Wells-Jensen. Thanks are also due to the three JIPA reviewers who offered further comments and suggestions. I alone am responsible for any remaining oversights in content or format. For initiating the IPA Braille project, and for comments and feedback at the early stages of its development, I wish to thank the International Council on English Braille, Darleen Bogart, Warren Figueiredo, and especially Jean Obi and the members of the Unified English Braille committee on linguistics and foreign languages. Heartfelt thanks to all who offered comments on the draft during the trial period (especially Alysha Jeans, Carlos Nash, and Martha Pamperin), and to everyone who used early drafts of IPA Braille in the classroom. 


\section{Appendix: IPA Braille charts (IPA revised to 2005)}

CONSONANTS (PULMONIC)

\begin{tabular}{|c|c|c|c|c|c|c|c|c|c|c|c|c|}
\hline & Bilabial & Labiodental & Dental & Alveolar & Postalveolar & Retro & & Palatal & Velar & Uvular & Pharyngeal & Glottal \\
\hline Plosive & 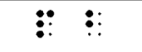 & & & :! : : & & : : : & : : : : & : : & $\vdots$ & : : : : : : & & $\vdots:$ \\
\hline Nasal & $\ddot{\vdots}$ & : : : : & & $\because !$ & & & : : : : & $::$ & : & :: : & & \\
\hline Trill & :؛: & & & $\vdots$ & & & & & & 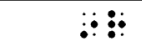 & & \\
\hline Tap or Flap & & : : : : & & 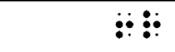 & & & : : : & & & & & \\
\hline Fricative & 苂: & :!: : : & : : : : : : & : & $\because \vdots: \vdots$ & :: : : : & : : : & !: : : & :ڤ & : : : : & : : : : : : & : : : : : \\
\hline Lateral fricative & & & & : : : : : : : & & & & & & & & \\
\hline Approximant & & $\vdots \vdots: \vdots$ & & $\vdots \vdots$ & & & : : : : & $\vdots:$ & :: : : & & & \\
\hline Lateral approximant & & & & $\bar{\vdots}:$ & & & :: :: & :: : : & 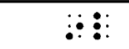 & & & \\
\hline
\end{tabular}

\section{CONSONANTS (NON-PULMONIC)}

\begin{tabular}{|c|c|c|c|c|c|}
\hline \multicolumn{2}{|r|}{ Clicks } & \multicolumn{2}{|c|}{ Voiced implosives } & \multicolumn{2}{|r|}{ Ejectives } \\
\hline ::: & Bilabial & $:::$ & Bilabial & $\vdots: \vdots$ & Examples: \\
\hline 苂: & Dental & :: : & Dental/alveolar & 苂: : : & Bilabial \\
\hline : & (Post)alveolar & 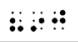 & Palatal & (: : : : : & Dental/alveolar \\
\hline$: \because: \vdots$ & Palatoalveolar & $::::$ & Velar & $\because: \vdots: \vdots$ & Velar \\
\hline$:: \vdots:$ & Alveolar lateral & 苂: : : & Uvular & : : : : : & Alveolar fricative \\
\hline
\end{tabular}




\section{OTHER SYMBOLS}

\begin{tabular}{|c|c|}
\hline 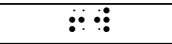 & Voiceless labial-velar fricative \\
\hline$\because:$ & Voiced labial-velar approximant \\
\hline$\because \because:$ & Voiced labial-palatal approximant \\
\hline$\therefore \because$ & Voiceless epiglottal fricative \\
\hline$\therefore:$ & Voiced epiglottal fricative \\
\hline : : & Epiglottal plosive \\
\hline$\because \because: \quad \vdots \because \vdots$ & Alveolo-palatal fricatives \\
\hline$\vdots \vdots:$ & Voiced alveolar lateral flap \\
\hline 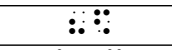 & Simultaneous $\int$ and $\mathrm{x}$ \\
\hline 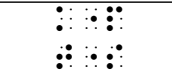 & $\begin{array}{l}\text { Affricates and double articulations can be represented by two symbols joined by a tie } \\
\text { bar if necessary. }\end{array}$ \\
\hline
\end{tabular}

\section{VOWELS}

\begin{tabular}{|c|c|c|c|}
\hline & Front & Central & Back \\
\hline \multirow[t]{2}{*}{ Close } & $\because \quad \because \vdots$ & $\therefore \because \vdots \quad \therefore$ & $\because \because$ \\
\hline & $\therefore \quad \therefore \because \because$ & & $\vdots$ \\
\hline \multirow[t]{2}{*}{ Close-mid } & $\because \quad \vdots$ & @ & $\because \because$ \\
\hline & & $\because$ & \\
\hline \multirow[t]{2}{*}{ Open-mid } & $\because \vdots \quad \therefore$ & 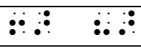 & $\ddot{\therefore}$ \\
\hline & $\because$ & $\because \because$ & \\
\hline Open & $\because \quad \therefore \quad \therefore$ & & 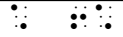 \\
\hline
\end{tabular}

\section{DIACRITICS}

\begin{tabular}{|c|c|c|c|c|c|}
\hline$\because:$ & Voiceless $\because: \because: \because: \because: \vdots$ & $\because \because$ & Breathy voiced : : : : : : & $\because \because$ & Dental : : :: : : : : : \\
\hline$\therefore:$ & Voiced : : : : : : : : : : & $\because \because$ & Creaky voiced : : :: : : : & $\because \because \because:$ & Apical : : : :: : : : : : \\
\hline$\because: \because$ & Aspirated :: ::: ::::: & $\because:$ & Linguolabial : :: :: $:$ : : : : & : & Laminal :: :: :: :: \\
\hline$\because \because$ & More rounded : : : & $\because \because$ & Labialized : : : : : : : : : : & $\because \because \vdots$ & Nasalized $\because: \because: \vdots$ \\
\hline$\because \because$ & Less rounded : : : & $\because \because:$ & Palatalized : : : : : : : : : & $\because \because \vdots$ & Nasal release $: \because: \because:$ \\
\hline$\therefore .8$ & Advanced :: :.: & $\because: \because:$ & Velarized :: ::: : : : : : :: : & $\because \because \vdots$ & Lateral release $:: \because:$ \\
\hline :. & Retracted $\because: .:$ & $\because \because:$ & Pharyngealized : : : : : : : : : & $\because \because:$ & $\begin{array}{l}\text { No audible release } \\
::: \vdots\end{array}$ \\
\hline$\because \because$ & Centralized $\because: \because:$ & $\because \because$ & \multicolumn{3}{|l|}{ Velarized or pharyngealized : : :: } \\
\hline$\because \ddot{:}$ & Mid-centralized $\because: \because:$ & $\because \vdots$ & \multicolumn{3}{|c|}{ Raised $\because: \vdots(: \vdots: \vdots=$ voiced alveolar fricative $)$} \\
\hline$\therefore$ & Syllabic :: : : & $\vdots$ & \multicolumn{3}{|c|}{ Lowered $\because \vdots$ (: $: \vdots=$ voiced bilabial approximant) } \\
\hline$:::$ & Non-syllabic $\because: \vdots:$ & $\because$ & \multicolumn{3}{|l|}{ Advanced Tongue Root $\because: \because$} \\
\hline$\because:$ & Rhoticity :: :: : : : : & $\because:$ & \multicolumn{3}{|l|}{ Retracted Tongue Root $\because: \vdots$} \\
\hline
\end{tabular}




\section{SUPRASEGMENTALS}

\begin{tabular}{|c|c|}
\hline$: \vdots:$ & Primary stress \\
\hline 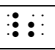 & Secondary stress \\
\hline$\because$ & Long $\because: \because$ \\
\hline$\because \because$ & Half-long $\because \because: \vdots$ \\
\hline$\because: \vdots$ & Extra-short $\because: \because:$ \\
\hline$: \vdots:$ & Minor (foot) group \\
\hline$:::$ & Major (intonation) group \\
\hline$\because$ & Syllable break : : : : : : \\
\hline$\because: \vdots$ & Linking (absence of a break) \\
\hline
\end{tabular}

\section{TONES AND WORD ACCENTS}

\begin{tabular}{|c|c|c|c|c|c|}
\hline \multicolumn{3}{|c|}{ LEVEL } & \multicolumn{3}{|c|}{ CONTOUR } \\
\hline$\because \vdots$ or & $:: \because:$ & Extra high & $\because \because \because 0$ & $\because: \vdots$ & Rising \\
\hline$\because \because$ & $\because \because:$ & High & $\because \because \because$ & 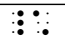 & Falling \\
\hline$\because \because \because$ & $\because \because \because$ & Mid & $\because \because$ & $\because \because:$ & High rising \\
\hline$\because \because \vdots$ & $\because \vdots$ & Low & $\because \because$ & $\because \vdots$ & Low rising \\
\hline$\because \vdots \vdots \vdots$ & : : : : & Extra low & $\because \because$ & $\because \because \because$ & Rising-falling \\
\hline$\vdots: \vdots$ & & Downstep & $\because$ & & Global rise \\
\hline$\vdots: \vdots$ & & Upstep & $:$ & & Global fall \\
\hline
\end{tabular}

\section{References}

AAWB (American Association of Workers for the Blind). 1977. Code of braille textbook formats and techniques. Louisville, KY: American Printing House for the Blind.

Ball, Martin J., John H. Esling \& B. Craig Dickson. 1995. The VoQS system for the transcription of voice quality. Journal of the International Phonetic Association 25, 71-80.

BANA (Braille Authority of North America). 1994. English braille, American edition, revised 2002. Louisville, KY: American Printing House for the Blind.

BANA. 1997a. Braille formats: Principles of print to braille transcription. Louisville, KY: American Printing House for the Blind.

BANA. 1997b. Music braille code. Louisville, KY: American Printing House for the Blind.

BANA. 2000. Computer braille code, revised 2000. Louisville, KY: American Printing House for the Blind.

BAUK (Braille Authority of the United Kingdom). 1990. The International Phonetic Alphabet (revised to 1979). London: Royal National Institute of Blind People.

BAUK. 2004. British braille: A restatement of Standard English Braille. London: Royal National Institute of Blind People.

BAUK. 2005. Braille mathematics notation. London: Royal National Institute of Blind People.

BAUK. 2006. Braille computer notation. London: Royal National Institute of Blind People.

BAUK. 2008. Braille science notation. London: Royal National Institute of Blind People.

Bogart, Darleen, Tim V. Cranmer \& Joseph E. Sullivan. 2000. Unifying the braille codes. In NLS, 160-181.

Dixon, Judith M. 2000. Refreshable braille displays: Their origins and evolution. In NLS, 348-373.

Eldridge, Carlton. 1979. Braille literacy: The best route to equal education. Journal of Visual Impairment and Blindness 73, 331-333. 
Englebretson, Robert (ed.). 2008. IPA Braille: An updated tactile representation of the International Phonetic Alphabet, 2 vols. Toronto: CNIB. http://www.iceb.org/icebipa.htm.

Gray, Sarah. 2006. Evaluation of the braille system used for phonetic transcription and suggestions for its improvement. BSc Honors thesis, University of Sheffield.

Hamp, Eric P. \& Hilda Catón. 1984. A fresh look at the sign system of the braille code. Journal of Visual Impairment and Blindness 78, 210-214.

Hampshire, Barry. 1981. Working with braille: A study of braille as a medium of communication. Paris: UNESCO Press.

IPA (International Phonetic Association). 1999. Handbook of the International Phonetic Association: A guide to the use of the International Phonetic Alphabet. Cambridge: Cambridge University Press.

Lorimer, Pamela. 1996. A critical evaluation of the historical development of the tactile modes of reading and an analysis and evaluation of researches carried out in endeavours to make the braille code easier to read and to write. Ph.D. thesis, School of Education, University of Birmingham. http://www.braille.org/papers/lorimer/title.html.

Mellor, C. Michael. 2006. Louis Braille: A touch of genius. Boston, MA: National Braille Press.

Merrick, W. Percy \& W. Potthoff. 1934. A braille notation of the International Phonetic Alphabet (1932) with key-words and specimen texts. London: The National Institute for the Blind.

Millar, Susanna. 1997. Reading by touch. New York: Routledge.

Nemeth, Abraham. 1972. The Nemeth Braille Code for mathematics and science notation. Louisville, KY: American Printing House for the Blind.

NLS (National Library Service for the Blind and Physically Handicapped). 2000. Braille into the next millennium. Washington, DC: Library of Congress, National Library Service for the Blind and Physically Handicapped.

Poole, William B. L. 1982. Braille as an autonomous script. In Richard H. Evensen (ed.), The International Conference on English Braille Grade 2, 181-198. Washington, DC: Library of Congress, National Library Service for the Blind and Physically Handicapped.

Pullum, Geoffrey K. \& William A. Ladusaw. 1996. Phonetic symbol guide, 2nd edn. Chicago, IL: University of Chicago Press.

Quick, Edith E. 1936. Announcement of 'W. P. Merrick \& W. Potthof [sic], A braille notation of the phonetic alphabet'. Le Maître Phonétique: Organe de l'Association Phonétique de Professeurs de Langues Vivantes 51, 51.

Ryles, Ruby. 1996. The impact of braille reading skills on employment, income, education, and reading habits. Journal of Visual Impairment and Blindness 90, 219-226.

Ryles, Ruby. 2000. Braille as a predictor of success. In NLS, 462-491.

Sadato, Norihiro. 2005. How the blind 'see' braille: Lessons from Functional Magnetic Resonance Imaging. Neuroscientist 11, 577-582.

Schroeder, Fredric K. 1989. Literacy: The key to opportunity. Journal of Visual Impairment and Blindness 83, 290-293.

Schroeder, Fredric K. 1996. Perceptions of braille usage by legally blind adults. Journal of Visual Impairment and Blindness 90, 210-218.

Schroeder, Fredric K. 2000. Braille in the workplace. In NLS, 296-313.

Stephens, Otis. 1989. Braille - implications for living. Journal of Visual Impairment and Blindness 83, 288-289.

Tenberken, Sabriye. 2003. My path leads to Tibet: The inspiring story of how one young blind woman brought hope to the blind children of Tibet. New York: Arcade.

UNESCO (United Nations Educational, Scientific and Cultural Organization). 1990. World braille usage, revised edition. Washington, DC: Library of Congress, National Library Service for the Blind and Physically Handicapped.

Wells-Jensen, Sheri. 2005. The braille International Phonetic Alphabet and other options: The blind student in the phonetics classroom. Journal of the International Phonetic Association 35, 221-230.

Wittenstein, Stuart Harold. 1993. Is braille a language? Journal of Visual Impairment and Blindness 87, $132-133$. 